OPEN ACCESS

Edited by:

Hongyue Dang

Xiamen University, China

Reviewed by:

Satoshi Ishii,

University of Minnesota, USA

Cuong Tu Ho,

Institute of Environmental Technology,

Vietnam

*Correspondence:

Tomoyuki Hori

hori-tomo@aist.go.jp

Yoko Katayama

katayama@cc.tuat.ac.jp

Specialty section:

This article was submitted to

Aquatic Microbiology,

a section of the journal

Frontiers in Microbiology

Received: 05 December 2016

Accepted: 20 January 2017

Published: 03 February 2017

Citation:

Ihara H, Hori T, Aoyagi T, Takasaki M and Katayama Y (2017)

Sulfur-Oxidizing Bacteria Mediate

Microbial Community Succession and

Element Cycling in Launched Marine

Sediment. Front. Microbiol. 8:152.

doi: 10.3389/fmicb.2017.00152

\section{Sulfur-Oxidizing Bacteria Mediate Microbial Community Succession and Element Cycling in Launched Marine Sediment}

\author{
Hideyuki Ihara ${ }^{1}$, Tomoyuki Hori ${ }^{2 *}$, Tomo Aoyagi ${ }^{2}$, Mitsuru Takasaki ${ }^{3}$ and Yoko Katayama ${ }^{4 *}$ \\ ${ }^{1}$ United Graduate School of Agricultural Science, Tokyo University of Agriculture and Technology, Fuchu, Japan, \\ ${ }^{2}$ Environmental Management Research Institute, National Institute of Advanced Industrial Science and Technology, Tsukuba, \\ Japan, ${ }^{3}$ Department of Food and Environmental Sciences, Faculty of Science and Engineering, Ishinomaki Senshu \\ University, Ishinomaki, Japan, ${ }^{4}$ Institute of Agriculture, Tokyo University of Agriculture and Technology, Fuchu, Japan
}

A large amount of marine sediment was launched on land by the Great East Japan earthquake. Here, we employed both on-site and laboratory studies on the launched marine sediment to investigate the succession of microbial communities and its effects on geochemical properties of the sediment. Twenty-two-month on-site survey showed that microbial communities at the uppermost layer ( $0-2 \mathrm{~mm}$ depth) of the sediment changed significantly with time, whereas those at the deeper layer (20-40 mm depth) remained nearly unchanged and kept anaerobic microbial communities. Nine months after the incidence, various sulfur-oxidizing bacteria (SOB) prevailed in the uppermost layer, in which afterwards diverse chemoorganotrophic bacteria predominated. Geochemical analyses indicated that the concentration of metals other than Fe was lower in the uppermost layer than that in the deeper layer. Laboratory study was carried out by incubating the sediment for 57 days, and clearly indicated the dynamic transition of microbial communities in the uppermost layer exposed to atmosphere. SOB affiliated in the class Epsilonproteobacteria rapidly proliferated and dominated at the uppermost layer during the first 3 days, after that Fe(II)-oxidizing bacteria and chemoorganotrophic bacteria were sequentially dominant. Furthermore, the concentration of sulfate ion increased and the $\mathrm{pH}$ decreased. Consequently, SOB may have influenced the mobilization of heavy metals in the sediment by metal-bound sulfide oxidation and/or sediment acidification. These results demonstrate that SOB initiated the dynamic shift from the anaerobic to aerobic microbial communities, thereby playing a critical role in element cycling in the marine sediment.

Keywords: sulfur-oxidizing bacteria, launched marine sediment, microbial community, high-throughput sequencing, Epsilonproteobacteria

\section{INTRODUCTION}

Coastal marine sediment governs the biogeochemical cycling of elements in the ocean, for instance as reservoirs of organic substances synthesized at the ocean surface (Middelburg et al., 1993) and of heavy metals (Morse and Luther, 1999). Marine sediment has diverse characteristics depending on both geographic features and human activities. On seafloor, depletion of dissolved oxygen 
was induced by aerobic degradation of the accumulated organic matters (Holmer and Kristensen, 1992; Cloern, 2001). Subsequently, residual organic matters are degraded by anaerobes such as sulfate-reducing bacteria (SRB). The resultant hydrogen sulfide reacts with metals including heavy metals. The reduced sulfur compounds are then preserved in the sediment (Jørgensen and Fenchel, 1974; Jørgensen, 1977). On the other hand, sulfur-oxidizing bacteria (SOB) are phylogenetically diverse and prevail in the sulfide-rich environments (Lenk et al., 2011, 2012; Dyksma et al., 2016). The accumulated reduced metal sulfides can be oxidized in the presence of oxidants by SOB, leading the heavy metal mobilization that has a critical impact on marine ecosystems. Seitaj et al. (2015) reported the seasonal change of two types of filamentous SOB affiliated to the family Beggiatoaceae in the class Gammaproteobacteria and the family Desulfobulbaceae in the class Deltaproteobacteria. However, characteristics of SOB colonizing in the sediment and their diversity are still poorly understood.

The Great East Japan Earthquake, which was the most severe earthquake recorded in Japan, occurred in the Tohoku region on 11 March 2011; the accompanying huge tsunami caused serious damage in coastal areas (Mimura et al., 2011). In addition to giving high salt stress to soil environments (Asano et al., 2013), the tsunami transported a large amount of marine sediment onto land. Up to now, the sediment has been intensively investigated to reveal its relationship with the surrounding coastal marine sediment (Tanaka et al., 2012). In addition, the risk of the sediment contaminated with heavy metals has been addressed (Kawabe et al., 2012; Tsuchiya et al., 2012; Sera et al., 2014; Nakamura et al., 2016). Concerning geochemical properties of the sediment, it has been reported that ignition loss (IL), an indicator of organic matter content, ranged from 1.2 to $16.3 \%$ and the $\mathrm{pH}$ range was 1.1-9.6 (Ministry of the Environment, 2011). For heavy metals, the content of As has been found to account for 1.4-32.1 mg/kg-sediment (Sera et al., 2011). However, most of the studies involved only transient data, and described the spatial and geochemical differences in the sediment. Time-course changes in the microbial and geochemical properties of the sediment after the exposure to terrestrial environments, therefore, remain to be elucidated.

Although our recent study on the launched marine sediment incubated under anaerobic conditions showed nearly unchanged microbial communities in the presence of sulfate, ferric iron and $\mathrm{CO}_{2}$ (Hori et al., 2014), and only amendment with nitrate facilitated the metabolic activities of anaerobic SOB in the classes Epsilonproteobacteria and Gammaproteobacteria (Aoyagi et al., 2015). Aerobic microbial activities are of considerable importance in the transformation of elements in the sediment because the surface of the sediment is always exposed to oxygen that is the highest energy-producing substrate for microbes. Nevertheless, very little is known about the structure and function of aerobic microbial communities in the sediment. In particular, SOB that use oxygen as electron donor are expected to play critical roles in the sediment because oxidation of sulfur compounds was the start of element cycle in the nitrate-supplemented incubation, while information on their physiological activities under oxic conditions is limited.
The objective of this study was to clarify microbial community succession in the launched marine sediment resulting from the exposure of the sediment to oxic conditions. To this end, we herein conducted deep sequencing of $16 \mathrm{~S}$ rRNA genes that has provided the detailed characteristics of microbial communities (Caporaso et al., 2011; Itoh et al., 2014; Mahmoudi et al., 2015; Navarro et al., 2015). In addition to the on-site survey for 22 months, laboratory incubation of the sediment was employed to examine the short-term microbial community dynamics and the changes in geochemical properties of the sediment. Monitoring at short intervals with a special focus on the exposure to atmosphere clarified the remarkable microbial community succession mediated by $\mathrm{SOB}$ and their involvement in the succeeding element cycling.

\section{MATERIALS AND METHODS}

\section{Sampling of Launched Marine Sediment}

Launched marine sediments by the Great East Japan Earthquake were collected at Higashi-matsushima, Miyagi, Japan (Table S1 and Figures S1-S3; $\left.38^{\circ} 25^{\prime} 49^{\prime \prime} \mathrm{N}, 141^{\circ} 14^{\prime} 39^{\prime \prime} \mathrm{E}\right)$. Color and texture of the uppermost layer ( $0-2 \mathrm{~mm}$ depth) were reddish brown and slightly dried, whereas those of the deeper layer were black and moist. Due to the visual appearances under the environmental conditions, it was assumed that the uppermost layer was oxic and the deep layer was anoxic. The sediments were sampled from 0 to 200-300 mm depth using a spade or a core sampler, transported to the laboratory under cool, and then separated vertically into the uppermost (0-2 $\mathrm{mm}$ depth) and deep (20-40 $\mathrm{mm}$ depth) layers. These sediment samples were stored at $-80^{\circ} \mathrm{C}$. To select sampling date for the main examination, prior analysis of the $16 \mathrm{~S}$ rRNA gene deep sequencing as mentioned below was performed in singlicate. Details of the prior analysis are shown in the supporting information (Figure S3). Based on the results of the analysis, we decided to use the sediments collected in December 2011, March 2012 and October 2013 for the examination of on-site changes in microbial communities and geophysical characteristics. The sediment collected in November 2012 was kept for around half a year at $4^{\circ} \mathrm{C}$ before conducting laboratory incubation. No significant change in microbial communities during the storage period was checked by the deep sequencing of $16 \mathrm{~S}$ rRNA genes.

\section{Laboratory Incubation of the Sediment}

The brock-state sediment was stored in a thick polyethylene bag to keep the humidity. After removing the air-exposed surface of the sediment, the inside part of the sediment remained under anoxic conditions was obtained for laboratory incubation. After thorough mixing, the sediment (approximately $200 \mathrm{~g}$ ) was placed in a polyethylene terephthalate container (reverse truncated cone: top, $12.9 \mathrm{~cm}$ dia.; bottom $9 \mathrm{~cm}$ dia.; height $6.5 \mathrm{~cm}$ ) to a depth of around $30 \mathrm{~mm}$. These procedures were conducted in a $100-$ L polyvinyl fluoride bag that was filled with nitrogen gas to minimize exposure of the sediment to air. The containers with the sediment were then placed in a $27-\mathrm{L}$ chamber containing water-soaked cotton to maintain $70-100 \%$ relative humidity, and incubated in the atmosphere in dark at $20-25^{\circ} \mathrm{C}$ for 57 days. 
Humidity and temperature were monitored with a data logger (Ondotori TR-72U; T\&D, Nagano, Japan). Two containers were sampled destructively from on days $1,3,7,14,28$, and 57 . Thus, a total of 12 containers ( 6 dates and 2 replication) were prepared in this experiment. The $0-2 \mathrm{~mm}$ depth (uppermost) and 12$16 \mathrm{~mm}$ depth (deep) layers of the sediments were collected in duplicate from each container. Consequently, the quadruplicate samples were used for subsequent analyses. The day 0 samples were collected in quadruplicate at the beginning of the experiment.

\section{Geochemical Analysis of the Sediment}

Geochemical properties measured in the uppermost layer of the on-site sediment were $\mathrm{pH}$, concentrations of sulfate and metals ( $\mathrm{Na}, \mathrm{Mg}, \mathrm{Al}, \mathrm{K}, \mathrm{Ca}, \mathrm{Fe}, \mathrm{Cr}, \mathrm{Cu}, \mathrm{As}, \mathrm{Se}, \mathrm{Cd}$, and $\mathrm{Pb}$ ). While the properties measured in the deep layer were ignition loss (IL), concentrations of ions $\left(\mathrm{Na}^{+}, \mathrm{K}^{+}, \mathrm{Mg}^{2+}, \mathrm{Ca}^{2+}, \mathrm{Cl}^{-}\right.$, and $\mathrm{SO}_{4}^{2-}$ ) and metals. For $\mathrm{pH}$ analysis, the sediment was suspended in ultrapure water at a ratio of 1:2.5 $(\mathrm{w} / \mathrm{w})$ and then the suspension was vortexed. Following the centrifugation at $21,500 \times \mathrm{g}$ for $1 \mathrm{~min}$ at $4{ }^{\circ} \mathrm{C}, \mathrm{pH}$ of the supernatant was measured with a $\mathrm{pH}$ electrode ( $\mathrm{pH}$ Meter M-12; Horiba, Kyoto, Japan). To determine IL, the sediment was dried at $100^{\circ} \mathrm{C}$ until the weight became constant, and then heated at $600^{\circ} \mathrm{C}$ for $2 \mathrm{~h}$. For measurement of ion concentrations, $0.03-1.3 \mathrm{~g}$ of sediment was suspended with $10 \mathrm{~mL}$ of ultra-pure water and shaken for $30 \mathrm{~min}$ at $4^{\circ} \mathrm{C}$. After centrifugation at $250 \times \mathrm{g}$ for $5 \mathrm{~min}$ at $4^{\circ} \mathrm{C}$, the supernatant was diluted with ultra-pure water, and filtered through a cellulose acetate filter $(0.2 \mu \mathrm{m}$ pore size). The resultant samples were analyzed by an ion chromatograph (883 Basic IC Plus; Metrohm Japan Ltd., Tokyo, Japan) equipped with a Metrosep A Supp 4 column $(250 \times 4 \mathrm{~mm})$ and a Metrosep A Supp 4/5 guard column (Metrohm Japan Ltd.) for anions, and an ion chromatograph (861 Advanced Compact IC; Metrohm Japan Ltd.) equipped with an IC YS-50 column $(4.6 \times 125 \mathrm{~mm})$ and an IC YS-G guard column (Showa Denko, Tokyo, Japan) for cations. Detailed method for metal analysis is shown in the Supplementary Information.

During the laboratory incubation of the sediment, IL, sulfate ion concentration, $\mathrm{pH}$, total carbon (TC), total nitrogen (TN), dissolved organic carbon (DOC), and dissolved nitrogen (DN) were determined. The sediment was suspended in ultra-pure water at a ratio of 1:10 $(\mathrm{w} / \mathrm{w})$ for measurement of sulfate ion concentration and at a ratio of 1:2.5 (w/w) for measurement of $\mathrm{pH}$. After shaking for $30 \mathrm{~min}$ and centrifugation at $250 \times \mathrm{g}$ for $5 \mathrm{~min}$ at $4^{\circ} \mathrm{C}$, sulfate ion concentration was measured with the ion chromatograph as described above. $\mathrm{pH}$ of the supernatant was measured with the $\mathrm{pH}$ electrode.

TC and TN of the dry sediment were measured with a carbon-nitrogen analyzer (MT-700; Yanako, Kyoto, Japan). For measurement of DOC and DN, the sediment was suspended in ultra-pure water at a ratio of 1:50 (w/w) and the solution was shaken at $4^{\circ} \mathrm{C}$ for $1 \mathrm{~h}$. After centrifugation at $250 \times \mathrm{g}$ for $5 \mathrm{~min}$ at $4{ }^{\circ} \mathrm{C}$, the supernatant was filtered through a cellulose acetate filter $(0.2 \mu \mathrm{m}$ pore size) and DOC and DN of the supernatant were measured using a total organic carbon analyzer (TOC-VE; Shimadzu, Kyoto, Japan) connected to a total nitrogen measuring unit (TNM-1; Shimadzu).

\section{Extraction of DNA from the Sediment, Polymerase Chain Reaction (PCR) Amplification, and Deep Sequencing of $16 \mathrm{~S}$ rRNA Genes}

DNA was extracted from the sediment in triplicate according to the bead-beating method described by Noll et al. (2005) with some modifications: $10-20 \mathrm{mg}$ of autoclaved skim milk was added to $100-500 \mathrm{mg}$ of the sediment before bead beating to improve the DNA recovery, and isopropyl alcohol was used instead of ethanol for precipitation of DNA (crude extract/isopropyl alcohol/3 M sodium acetate was 10:9:1 [v/v/v]). Subsequently, RNA in the crude DNA extract was removed with RNase A (Nippon Gene, Tokyo, Japan). DNA concentration was determined spectrophotometrically (NanoDrop 2000; Thermo Scientific, Kanagawa, Japan). Eighteen and 39 DNA extracts from the on-site and incubated sediments, respectively, were utilized for the construction of deep sequencing libraries.

PCR targeting on the V4 region of 16S rRNA genes was conducted with the primer set $515 \mathrm{~F}\left(5^{\prime}-\right.$ GTGCCAGCMGCCGCGGTAA-3')/806R( $\left(5^{\prime}\right.$-GGACTACHVG GGTWTCTAA-T-3') attached to sequences for the adapter region. The reverse primer was encoded with 12-bp barcodes for multiplex sequencing (Caporaso et al., 2012). The PCR mixture included $10 \mu \mathrm{l}$ of $5 \times \mathrm{Q} 5$ buffer, $1 \mu \mathrm{l}$ of $2.5 \mathrm{mM}$ dNTP, $2 \mu \mathrm{l}$ of each of $10 \mathrm{pM} 515 \mathrm{~F}$ and $806 \mathrm{R}$ primers, $0.5 \mu \mathrm{l}$ of DNA polymerase (Q5; NEB, Tokyo, Japan), $10 \mathrm{ng}$ of template DNA, and sterile ultra-pure water for a final volume of $50 \mu \mathrm{l}$. PCR amplification was performed as follows: initial denaturation at $98^{\circ} \mathrm{C}$ for $1.5 \mathrm{~min}$, and then 20 or 30 cycles consisting of denaturation at $98^{\circ} \mathrm{C}$ for $10 \mathrm{~s}$, annealing at $55^{\circ} \mathrm{C}$ for $30 \mathrm{~s}$, and extension at $72^{\circ} \mathrm{C}$ for $30 \mathrm{~s}$, followed by final extension at $72^{\circ} \mathrm{C}$ for $2 \mathrm{~min}$. The accuracy of amplification was confirmed by electrophoresis on $1.2 \%$ agarose gel. The concentration of PCR products was similar in spite of the different cycle numbers applied, which imply no or little influence of the cycle numbers on the results of the subsequent deep sequencing.

Purification of PCR products prior to deep sequencing of $16 \mathrm{~S}$ rRNA genes was performed as described by Hori et al. (2014). The prepared DNA segments were subjected to pairedend sequencing with a 300-cycle MiSeq reagent kit (Illumina, Tokyo, Japan), and then a MiSeq sequencer (Illumina). The obtained sequences were aligned using a Burrows-Wheeler Aligner ver 0.5.9. and filtered by quality value $30(\mathrm{Q} 30)$ by command lines in the software QIIME ver 1.7.0. (Caporaso et al., 2010). Chimeric sequences were removed by using the Mothur software (Schloss et al., 2009). The software QIIME was used for phylogenetic classification of operational taxonomic units (OTUs) with a cut-off value of $97 \%$ similarity. Using this software, the $\alpha$-diversity indices and the weighted UniFrac distances for principal coordinate analysis (PCoA) were calculated. Some of the predominant OTUs were compared to sequences deposited in the database of the DNA Data Bank of Japan (DDBJ) using the Basic Local Alignment Search Tool (BLAST) to determine their closest relatives. The sequence data obtained in this study have been deposited in the DDBJ database under accession numbers DRA004739 and DRA004740. 


\section{Quantitative PCR (qPCR) of the Incubated Sediment}

To measure the number of copies of 16S rRNA genes in the sediment incubated in the laboratory, qPCR was conducted in duplicate using Premix Ex Taq II (Takara Bio Inc., Shiga, Japan) and a Thermal Cycler Dice Real Time System II (Takara Bio Inc.). The 515F/806R primer set was used and the mixture was prepared according to the manufacturer's instructions. PCR amplification was performed as follows: initial denaturation at $95^{\circ} \mathrm{C}$ for $30 \mathrm{~s}$, and then 45 cycles consisting of $95^{\circ} \mathrm{C}$ for $5 \mathrm{~s}$, and $61^{\circ} \mathrm{C}$ for $30 \mathrm{~s}$. A standard curve was constructed using PCR products from the 16S rRNA gene from Escherichia coli with the primer set 27F (5'-AGAGTTTGATCCTGGCTCAG-3')/1525R (5'-AAAGGAGGTGATCCAGCC-3').

\section{RESULTS}

\section{Microbial Communities in the On-Site Sediment}

Deep sequencing of $16 \mathrm{~S}$ rRNA genes was carried out to investigate microbial communities in the on-site sediment. The total number of sequences obtained from 18 sediment samples was around 7.2 hundred thousand, corresponding to an average of 39,775 sequences per library (Table S2). The $\alpha$-diversity indices (i.e., Chao1, Shannon, and Simpson reciprocal) were calculated by using an equal number of sequences $(30,789)$ subsampled 10 times from original libraries. These values were lower in the uppermost layer than in the deep layer, indicating that the uppermost layer had more specified and less diverse microbial communities than those in the deep layer.

PCoA illustrated that microbial communities in the uppermost layers of the sediments changed drastically during the monitored period (Figure S4). Phylogenetic information of the entire structures and predominant OTUs is shown in Figure $\mathbf{1}$ and Table S3. Figure 1 shows that the phylum Proteobacteria dominated in both the uppermost and deep layers, which accounted for $42.0-72.4 \%$ and $29.9-42.2 \%$ of the relative abundance, respectively. The class Gammaproteobacteria was predominant in the uppermost layer (relative abundances: 10.9$42.0 \%$ ), and analysis at the major order showed the clear bacterial succession depending on the sampling date. More specifically, the order Thiotrichales was predominant in December 2011 (10.5\%), whereas the order Xanthomonadales became dominant in October 2013 (37.7\%) (Figure 1B). It is worth noting that the dominant constituent of Thiotrichales detected in the sediment was only SOB belonging in the genus Thiomicrospira (Table S3). With respect to other SOB, the genus Sulfurimonas in the class Epsilonproteobacteria was dominant in December 2011 (Figure 1C). Also, Pandoraea thiooxydans (OTU 1598) in the class Betaproteobacteria accounted for $12.4 \%$ in the same time (Table S3). These results indicate that SOB was present and may have performed sulfur oxidation in the uppermost layer of the sediment. In October 2013, chemoorganotrophic bacteria in the order Xanthomonadales and the phylum Actinobacteria became dominant in the uppermost layer (Figures 1A,B). Organic compounds including carbon products of SOB would serve as substrate for the chemoorganotrophs.

In contrast, PCoA and phylogenetic analysis showed microbial communities in the deep layers remained nearly unchanged over 22 months (Figure S4 and Figure 1). The class Deltaproteobacteria was dominant (19.0-25.9\%) and mainly comprised the three orders (i.e., Desulfobacterales, Desulfuromonadales and Syntrophobacterales) (Figure 1D). These taxa are known to include obligate anaerobic SRB, implying that the sulfate reduction was retained under the presumably anoxic conditions of the deep layer, which is in accordance with findings obtained in our previous studies (Hori et al., 2014; Aoyagi et al., 2015).

\section{Geochemical Properties of the On-Site Sediment}

Geochemical analyses were conducted to characterize chemical components of the sediment and their time-dependent changes under oxic conditions. IL and ion concentrations of the deep layer were consistently high, indicating that the sediment exhibited the high accumulation of organic matters and the salinity, and these levels were kept for at least the period monitored around 22 months (Table 1). The most abundant metal in the deep layer was $\mathrm{Al}$, followed by $\mathrm{Fe}$ (Table 2). Metals, such as $\mathrm{Na}, \mathrm{Mg}, \mathrm{K}$, and $\mathrm{Ca}$ that are common in natural environments, were also found in the deep layer. Concentrations of metals other than Fe were apparently lower in the uppermost layer than those in the deep layer. While $\mathrm{pH}$ of the uppermost layer in March 2012 was neutral (pH 7.1), that in December 2011 was acidic ( $\mathrm{pH} 4.3$ ) (Table S1). The acidification of the uppermost layer may have facilitated the metal mobilization, resulting in the low concentration of the metals. High concentrations of sulfate in October 2013 implied that sulfur oxidation occurred in the uppermost layer. Although concentrations of heavy metals such as $\mathrm{Cu}, \mathrm{As}, \mathrm{Cd}$ and $\mathrm{Pb}$ were high in the sediment compared to those in soils (Iimura, 1981), their concentrations were sufficiently below the environmental standard values in the Soil Contamination Countermeasure Act of Japan (http://www.env. go.jp/en/water/soil/contami_cm.pdf).

\section{Succession of the Sediment Microbial Communities during Laboratory Incubation}

The on-site sediment was influenced by various environmental factors such as air exposure, insolation and rainfall, and it makes difficult to evaluate the relationship between the succession of microbial communities and the surrounding environment conditions. Thus, laboratory incubation was conducted to monitor the microbial responses to environmental changes more concretely under controlled conditions. We focused on the exposure to atmosphere because the microbial metabolism, such as chemoorganotrophic and chemolithotrophic transformation, are highly affected by redox conditions.

Results from qPCR showed that there was no significant difference in the copy number of $16 \mathrm{~S}$ rRNA genes between the uppermost and deep layers (Table S4). The total number of sequences obtained from 39 sediment samples was around 2.2 
A Alphaproteobacteria - Gammaproteobacteria - Epsilonproteobacteria - Bacteroidetes

Cyanobacteria

- Firmicutes

- Actinobacteria

- Other bacteria

Others

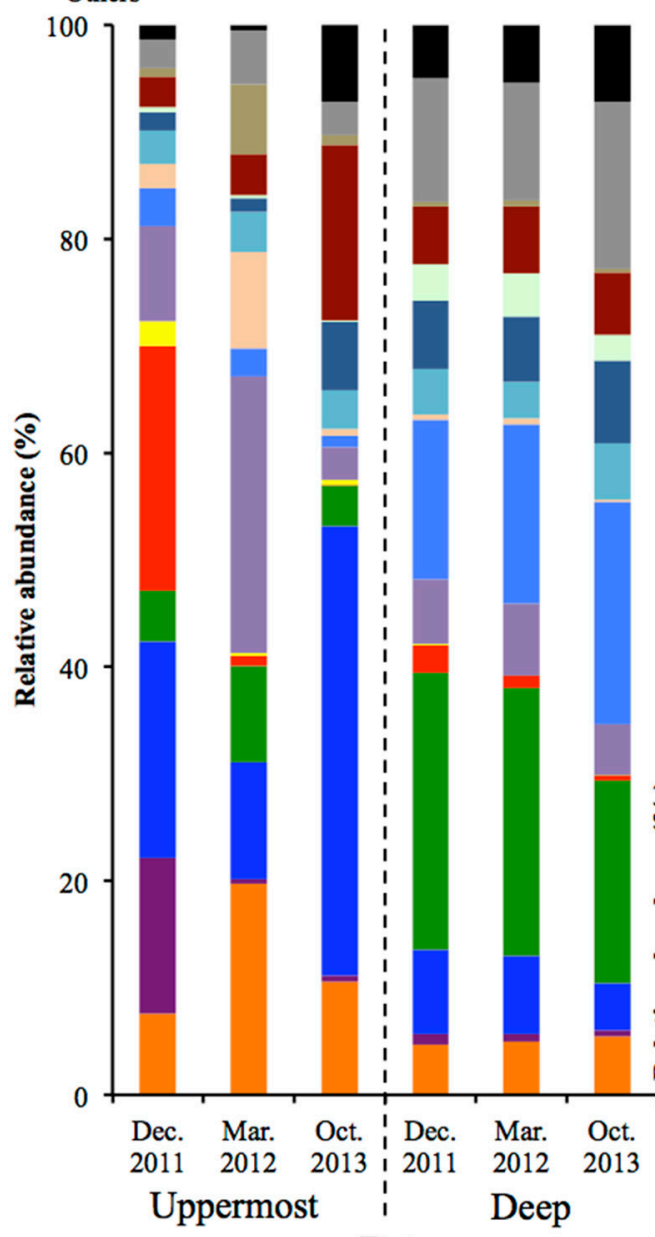

Date
- Betaproteobacteria - Deltaproteobacteria

Zetaproteobacteria

- Chloroflexi

- Planctomycetes

Acidobacteria

Verrucomicrobia

- Archaea
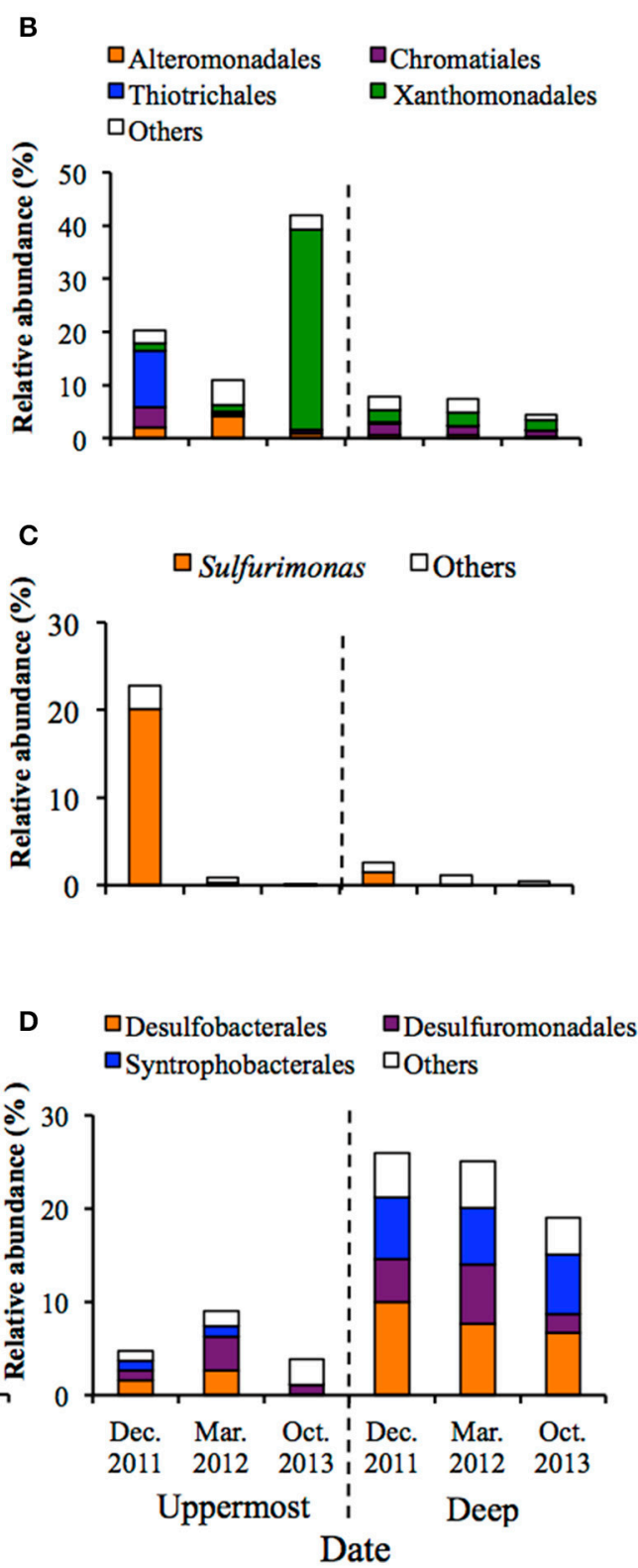

FIGURE 1 | Microbial community structures in the uppermost (0-2 mm depth) and deep (20-40 mm depth) layers of the on-site sediments based on the 16S rRNA gene analysis $(n=3)$. The bars indicate average values of three replications. Sediment samples were collected in December 2011 , March 2012 and October 2013. (A) Microbial communities are categorized by phylum except for Proteobacteria that is shown by class. The fraction of the dominant phylotypes ( $>3 \%$ of each library) in the classes Gammproteobacteria (B), Epsilonproteobacteria (C), and Deltaproteobacteria (D) are shown in the histograms.

TABLE 1 | Changes of IL and ion concentrations in the on-site sediment ${ }^{\mathrm{a}}(n=3)$

\begin{tabular}{|c|c|c|c|c|c|c|c|}
\hline Sampling date & IL (\%) & \multicolumn{6}{|c|}{ Ion concentration (mg/kg dry sediment) } \\
\hline Mar. 2012 & $11.4 \pm 0.9$ & $11,743 \pm 4195$ & $1008 \pm 291$ & $1473 \pm 84$ & $2391 \pm 1205$ & $16,081 \pm 6564$ & $4752 \pm 1324$ \\
\hline Oct. 2013 & $10.2 \pm 0.3$ & $4473 \pm 1264$ & $884 \pm 113$ & $935 \pm 120$ & $2447 \pm 1094$ & $5461 \pm 1418$ & $6827 \pm 1882$ \\
\hline
\end{tabular}

${ }^{a}$ The deep (20-40 mm depth) layer sediments were used for the analysis. The symbol " \pm " means the standard deviation of three replications. There was the significant difference in $\mathrm{Cl}^{\prime}$ between the sediment in March 2012 and October $2013(p<0.05)$. 
TABLE 2 | Changes of metal concentrations in the on-site sediment.

\begin{tabular}{|c|c|c|c|c|c|c|c|}
\hline \multirow[t]{2}{*}{ Layer } & \multirow[t]{2}{*}{ Sampling date } & \multicolumn{6}{|c|}{ Metal concentration (mg/kg dry sediment) } \\
\hline & & $\mathrm{Na}$ & Mg & Al & $\mathbf{K}$ & $\mathbf{C a}$ & $\mathbf{F e}$ \\
\hline Uppermost $^{a}$ & Mar. 2012 & 15,650 & 10,626 & 60,561 & 5642 & 8173 & 148,088 \\
\hline \multirow[t]{4}{*}{ Deep ${ }^{b}$} & Dec. 2011 & $16,673 \pm 808$ & $17,045 \pm 398$ & $113,292 \pm 4022$ & $8912 \pm 182$ & $10,242 \pm 38$ & $72,139 \pm 3467$ \\
\hline & Mar. 2012 & $20,477 \pm 1426$ & $18,130 \pm 710$ & $115,629 \pm 2808$ & $9083 \pm 118$ & $9600 \pm 343$ & $73,939 \pm 1514$ \\
\hline & Oct. 2013 & $12,035 \pm 1367$ & $15,440 \pm 1649$ & $102,379 \pm 11,373$ & $8456 \pm 722$ & $9546 \pm 865$ & $69,636 \pm 5783$ \\
\hline & & $\mathrm{Cr}$ & $\mathrm{Cu}$ & As & Se & $\mathbf{C d}$ & $\mathbf{P b}$ \\
\hline Uppermost ${ }^{\mathrm{a}}$ & Mar. 2012 & 30.7 & 44 & 32.5 & 1.8 & 0.19 & 30.5 \\
\hline \multirow[t]{3}{*}{ Deep $^{b}$} & Dec. 2011 & $57.2 \pm 1.7$ & $123 \pm 0.3$ & $47.8 \pm 1.7$ & $2.5 \pm 0.1$ & $1.1 \pm 0.0$ & $52.1 \pm 0.4$ \\
\hline & Mar. 2012 & $57.6 \pm 1.6$ & $120 \pm 4.1$ & $47.7 \pm 1.4$ & $3.0 \pm 0.1$ & $1.1 \pm 0.1$ & $50.1 \pm 0.6$ \\
\hline & Oct. 2013 & $53.1 \pm 5.2$ & $118 \pm 11.1$ & $43 \pm 2.8$ & $2.8 \pm 0.5$ & $1.1 \pm 0.1$ & $53.3 \pm 0.4$ \\
\hline
\end{tabular}

a Sediment sample was collected at 0-2 mm depth from the surface. The measurement was conducted in singlicate because the quantity of obtained sample was small.

bSediment samples were collected at 20-40 mm depth from the surface $(n=2)$ and the symbol " \pm " means the variation between two replications.

million, corresponding to an average of 56,403 sequences per library. The $\alpha$-diversity indices were calculated by using an equal number of sequences $(31,950)$ subsampled 10 times from original libraries. The values were lower in the uppermost layer than in the deep layer, corresponding with the on-site survey that indicated low microbial diversity in the uppermost layer (Table S2). PCoA showed notable shifts in the uppermost-layer microbial communities (Figure 2), strongly suggesting that the exposure to the atmosphere immediately altered the physiological properties of microbes in the uppermost layer.

Figure 3 shows the succession of microbial communities of the sediment during the incubation, and the most predominant 7 OTUs in the uppermost layer at each sampling date are summarized in Table 3 and Table S5. Microbial communities in the uppermost layer changed considerably with incubation time. The relative abundance of the class Epsilonproteobacteria increased dramatically from $7.5 \%$ at day 0 to $61.5 \%$ at day 3 (Figure 3B). The family Helicobacteraceae was the most dominant taxon found in this class, and comprised the genera Sulfuricurvum and Sulfurimonas that are known as important SOB in marine sediment (Kodama and Watanabe, 2004). These dramatic succession from anaerobic chemoorganotrophic bacteria to SOB in the microbial communities strongly suggest the importance of sulfur oxidation processes in the launched marine sediment under oxic conditions. Growth of some SOB (e.g., Sulfurovum lithotrophicum) that did not prevail under nitrate-reducing conditions in the previous study (Aoyagi et al., 2015) was enhanced under oxic conditions in this study. The rapid proliferation of the class Epsilonproteobacteria was followed by increases in the classes Zetaproteobacteria and Betaproteobacteria (Figure 3A). Phylogenetic analysis at the OTU level showed the predominance of OTUs closely related to Mariprofundus ferrooxydans (EF493244) and Gallionella sp. (HQ117915), both of which exhibit Fe(II)-oxidizing activity (Hallbeck and Pedersen, 2005; Emerson et al., 2007). This implicates that ferrous iron oxidation occurred subsequent to, or in parallel with, the

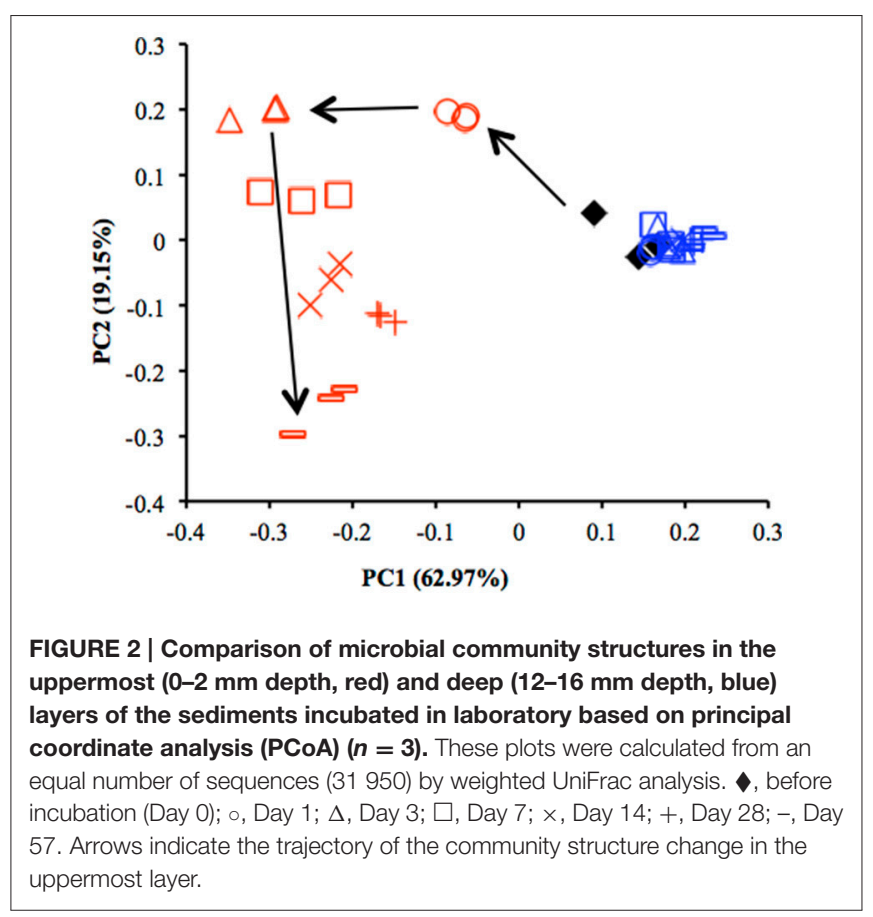

sulfur oxidation by SOB. At the end of the incubation, the class Gammaproteobacteria and the phylum Actinobacteria became dominant. Because the family Streptomycetaceae in the Actinobacteria and the orders Xanthomonadales and Methylococcales in the Gammaproteobacteria are known to exhibit chemoorganotrophy (Bowman, 2005; Saddler and Bradbury, 2005; Kämpfer, 2012), it is considered that these bacteria became metabolically active in the uppermost layer after the proliferation of chemolithotrophic bacteria (i.e., SOB and $\mathrm{Fe}(\mathrm{II})$-oxidizing bacteria $[\mathrm{FeOB}])$.

A variety of SOB became dominant according to the time of the incubation. Specifically, Sulfurovum lithotrophicum (OTU 43060), Sulfurovum aggregans related species (OTU 
A

- Alphaproteobacteria

- Gammaproteobacteria

- Epsilonproteobacteria

- Bacteroidetes

- Planctomycetes

- Actinobacteria

WS3

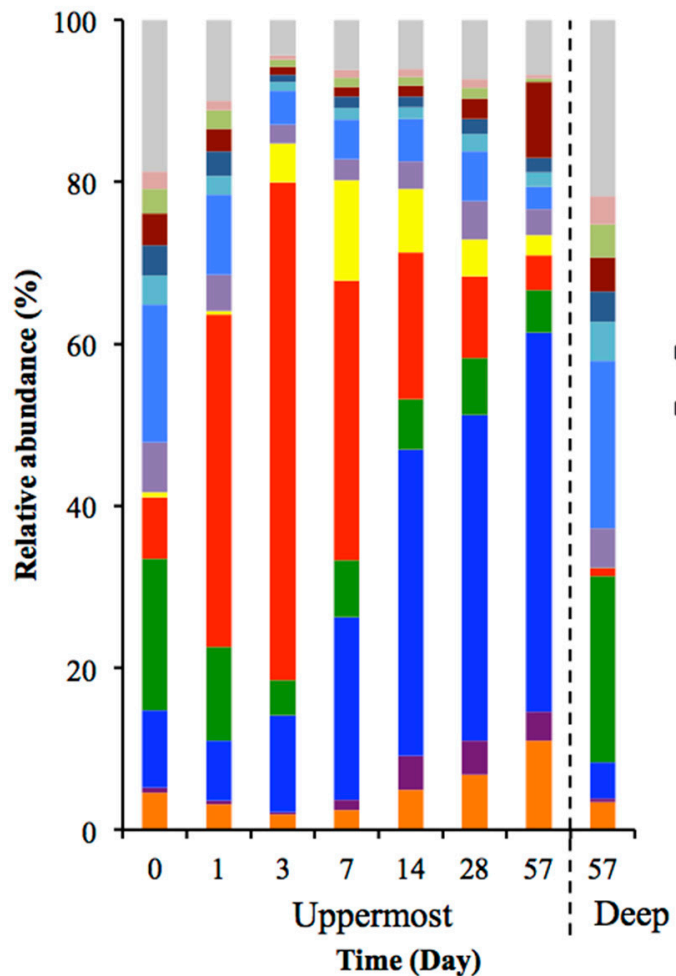

- Betaproteobacteria

- Deltaproteobacteria

Zetaproteobacteria

- Chloroflexi

- Firmicutes

Crenarchaeota

Others
B

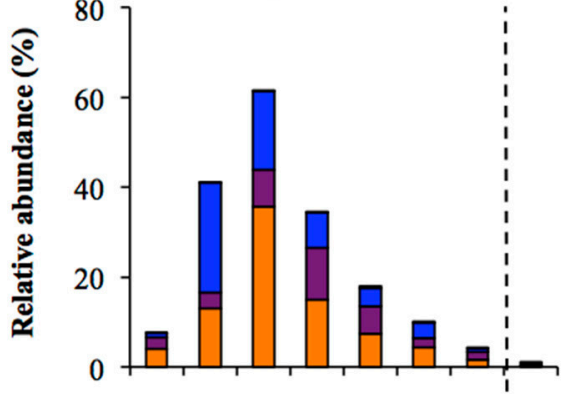

C
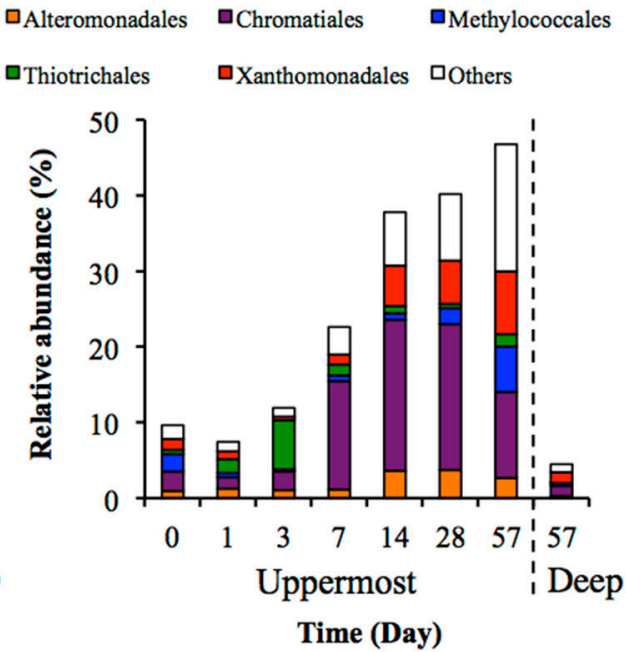

FIGURE 3 | Transition of microbial community structures in the uppermost (0-2 mm depth) and deep (12-16 mm depth) layers of the sediments incubated in laboratory $(\boldsymbol{n}=\mathbf{3})$. The bars indicate average values of three replications. Microbial communities in the deep layers (except for that at day 57) were not exhibited because the community structures were quite similar during the incubation period. (A) Microbial communities are categorized by phylum except for Proteobacteria that is shown by class. The fraction of the dominant phylotypes ( $>3 \%$ of each library) in the classes Epsilonproteobacteria (B) and Gammaproteobacteria (C) are shown in the histograms.

25387), Sulfurimonas denitrificans (OTU 30483), Thiomicrospira psychrophila (OTU 21731) and Thiomicrospira crunogena (OTU 36501) were predominant at days 1-3, whereas Thioalkalispira microaerophila (OTU 45161) and Thiohalophilus thiocyanatoxydans related species (OTUs 16111 and 45198) increased after day 14 (Table 3). The successive dominance of SOB suggests that sulfur oxidation have an advantage over chemoorganotrophy in the organic compounds- and sulfides-rich sediment during the incubation.

Microbial community structures in the deep layers during the incubation were quite similar each other, therefore, the representative data at day 57 is presented in Figure 3. The microbial communities consisted mainly of the class Deltaproteobacteria and the phylum Chloroflexi, which is consistent with the microbial communities in the deep layers of the on-site survey (Figure 1).

\section{Change in Geochemical Properties of the Sediment during Laboratory Incubation}

Water content of the sediment was in the range of 55.9-58.8\% during the laboratory incubation. The concentration of sulfate ion in the uppermost layer increased considerably from 4075 to $9219 \mathrm{mg} / \mathrm{kg}$ dry weight ( $\mathrm{dw})$, and $\mathrm{pH}$ decreased from 7.2 to 4.7 (Figure 4), indicating the sulfate formed by SOB acidified the sediment. Rate of the sulfate accumulation can be divided into two stages: faster rates during the first week (about 377 $\mathrm{mg} / \mathrm{kg} \mathrm{dw} /$ day) and slower rates in the succeeding period (about $50 \mathrm{mg} / \mathrm{kg} \mathrm{dw} /$ day). In particular, the sulfate-accumulating rate in the first 3 days reached a maximum value of $705 \mathrm{mg} / \mathrm{kg}$ dw/day (i.e., $300 \mathrm{mg} / \mathrm{kg} \mathrm{ww} /$ day). The IL in the uppermost and deep layers did not differ between the beginning and end of the incubation (Figure S5A). TC content significantly increased in the uppermost layer and the value reached $20.3 \mathrm{~g} / \mathrm{kg} \mathrm{dw}$ at the 
TABLE 3 | Most abundant OTUs and their closely related species found in the uppermost layer of the sediment incubated in laboratory.

\begin{tabular}{|c|c|c|c|c|c|c|c|c|}
\hline $\begin{array}{l}\text { Incubation } \\
\text { day }\end{array}$ & OTU No. & Closest relative species $^{a}$ & $\begin{array}{c}\text { Similarity } \\
(\%)\end{array}$ & Accession No. & Phylum/Class ${ }^{\text {b }}$ & $\begin{array}{c}\text { Relative } \\
\text { abundance }(\%)^{\mathrm{c}}\end{array}$ & $p$-valued & $\begin{array}{l}\text { Putative } \\
\text { function }^{e}\end{array}$ \\
\hline \multirow[t]{7}{*}{1} & 43060 & Sulfurovum lithotrophicum & 98 & CP011308 & Epsilonproteobacteria & $14.4 \pm 0.3$ & $<0.001^{\star \star}$ & $\mathrm{SO}, \mathrm{NR}$ \\
\hline & 42344 & Sulfurimonas autotrophica & 92 & CP002505 & Epsilonproteobacteria & $9.7 \pm 0.3$ & $<0.001^{\star \star}$ & Unknown \\
\hline & 25387 & Sulfurovum aggregans & 96 & AB889689 & Epsilonproteobacteria & $9.2 \pm 0.4$ & $<0.001^{\star \star}$ & $\mathrm{SO}, \mathrm{NR}$ \\
\hline & 49085 & Sulfurimonas sp. OH30-7C-S & 90 & AB304903 & Epsilonproteobacteria & $2.9 \pm 0.5$ & $0.002^{\star \star}$ & Unknown \\
\hline & 27532 & Sulfurimonas sp. MA01 & 95 & AB930173 & Epsilonproteobacteria & $1.6 \pm 0.6$ & $0.04^{\star}$ & Unknown \\
\hline & 49878 & Desulfobulbus elongatus & 92 & СР002364 & Deltaproteobacteria & $1.6 \pm 0.0$ & $0.005^{\star \star}$ & Unknown \\
\hline & 21731 & Thiomicrospira psychrophila & 100 & AJ404732 & Gammaproteobacteria & $1.2 \pm 0.2$ & $0.001^{\star \star}$ & $\mathrm{SO}$ \\
\hline \multirow[t]{7}{*}{3} & 42344 & Sulfurimonas autotrophica & 92 & CP002505 & Epsilonproteobacteria & $30.7 \pm 6.4$ & $0.001^{\star \star}$ & Unknown \\
\hline & 25387 & Sulfurovum aggregans & 96 & AB889689 & Epsilonproteobacteria & $9.0 \pm 3.4$ & $0.01^{\star}$ & $\mathrm{SO}, \mathrm{NR}$ \\
\hline & 43060 & Sulfurovum lithotrophicum & 98 & CP011308 & Epsilonproteobacteria & $8.0 \pm 2.1$ & $0.005^{\star \star}$ & $\mathrm{SO}, \mathrm{NR}$ \\
\hline & 49085 & Sulfurimonas sp. OH30-7C-S & 90 & AB304903 & Epsilonproteobacteria & $4.1 \pm 0.8$ & $0.003^{\star \star}$ & Unknown \\
\hline & 32337 & Mariprofundus ferrooxydans & 96 & EF493244 & Zetaproteobacteria & $3.9 \pm 0.2$ & $<0.001^{\star \star}$ & $\mathrm{FeO}$ \\
\hline & 36501 & Thiomicrospira crunogena & 100 & L40810 & Gammaproteobacteria & $3.7 \pm 0.9$ & $0.002^{\star \star}$ & $\mathrm{SO}$ \\
\hline & 30483 & Sulfurimonas denitrificans & 98 & L40808 & Epsilonproteobacteria & $2.7 \pm 1.1$ & $0.02^{*}$ & $\mathrm{SO}, \mathrm{NR}$ \\
\hline \multirow[t]{7}{*}{14} & 45161 & Thioalkalispira microaerophila & 98 & AF481118 & Gammaproteobacteria & $18.3 \pm 1.9$ & $<0.001^{\star \star}$ & $\mathrm{SO}, \mathrm{NR}$ \\
\hline & 32337 & Mariprofundus ferrooxydans & 96 & EF493244 & Zetaproteobacteria & $4.8 \pm 0.8$ & $<0.001^{\star \star}$ & $\mathrm{FeO}$ \\
\hline & 6816 & Gallionella sp. PN013 & 97 & HQ117915 & Betaproteobacteria & $4.0 \pm 0.2$ & $<0.001^{\star \star}$ & $\mathrm{FeO}$ \\
\hline & 42344 & Sulfurimonas autotrophica & 92 & СР002505 & Epsilonproteobacteria & $3.9 \pm 0.6$ & $0.001^{\star \star}$ & Unknown \\
\hline & 6961 & Dyella ginsengisoli & 100 & KC129050 & Gammaproteobacteria & $3.4 \pm 2.1$ & 0.05 & ChemO \\
\hline & 30483 & Sulfurimonas denitrificans & 98 & $\llcorner 40808$ & Epsilonproteobacteria & $3.1 \pm 0.4$ & $<0.001^{\star \star}$ & $\mathrm{SO}, \mathrm{NR}$ \\
\hline & 16111 & Thiohalophilus thiocyanatoxydans & 96 & DQ469584 & Gammaproteobacteria & $2.9 \pm 0.5$ & $0.001^{\star \star}$ & $\mathrm{SO}, \mathrm{NR}$ \\
\hline \multirow[t]{7}{*}{57} & 45161 & Thioalkalispira microaerophila & 98 & AF481118 & Gammaproteobacteria & $9.0 \pm 1.7$ & $0.001^{\star \star}$ & $\mathrm{SO}, \mathrm{NR}$ \\
\hline & 24485 & Streptomyces vitaminophilus & 99 & AB184589 & Actinobacteria & $8.1 \pm 2.5$ & $0.005^{\star \star}$ & ChemO, NR \\
\hline & 908 & Salinispirillum marinum & 93 & KJ195687 & Gammaproteobacteria & $5.9 \pm 1.7$ & $0.004^{\star \star}$ & Unknown \\
\hline & 23047 & Oleiagrimonas soli & 98 & JQ658406 & Gammaproteobacteria & $4.8 \pm 1.2$ & $0.002^{\star \star}$ & ChemO, NR \\
\hline & 30112 & Thiohalophilus thiocyanatoxydans & 92 & DQ469584 & Gammaproteobacteria & $3.0 \pm 1.2$ & $0.01^{*}$ & Unknown \\
\hline & 45198 & Thiohalophilus thiocyanatoxydans & 96 & DQ469584 & Gammaproteobacteria & $2.6 \pm 0.7$ & $0.003^{\star \star}$ & $\mathrm{SO}, \mathrm{NR}$ \\
\hline & 6961 & Dyella ginsengisoli & 100 & KC129050 & Gammaproteobacteria & $2.4 \pm 0.4$ & $0.001^{\star *}$ & ChemO \\
\hline
\end{tabular}

a The closely related species were assigned on BLAST in the DDBJ.

${ }^{b}$ The OTUs were characterized phylogenetically by using the QIIME software.

${ }^{c}$ The symbol " \pm " means the standard deviation of three replications.

${ }^{d} p$-values indicate whether the relative abundance of OTU was significantly high comparing with that in the deep layer: ${ }^{*} p<0.05,{ }^{* *} p<0.01$.

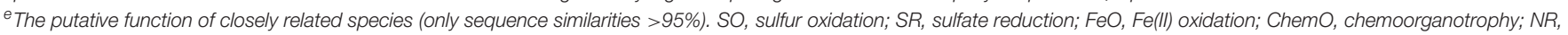
nitrate reduction.

end of the incubation, whereas TN content showed no significant change (Figures S5B,C). In contrast, the DOC concentrations in both the uppermost and deep layers and the DN concentration in the uppermost layer exhibited the significant decreases (Figures S5D,E). The decreasing rate of DOC was notably higher in the uppermost layer than in the deep layer. Especially, the significant decrease in DOC in the uppermost layer was possibly due to the enhanced activities of chemoorganotrophs by the exposure to atmosphere.

\section{DISCUSSION}

SOB in the class Epsilonproteobacteria were predominant during the early phase of the laboratory incubation (days 1-3), whereas SOB in the class Gammaproteobacteria were predominant during the latter phase (Figure 3 and Table 3 ). These differences might be explained by the distinct metabolic strategies of sulfur oxidation in these SOB. The phylum Proteobacteria is known to have several pathways for sulfur oxidation. The Gammaproteobacteria has an energy-producing pathway that is kinetically advantageous if oxygen and reduced sulfur compounds are steadily supplied, while the Epsilonproteobacteria has versatile energy-producing pathways to adapt to transient environmental conditions (Yamamoto and Takai, 2011). Thus, it is plausible that the Epsilonproteobacteria dominated at the earlier stage of the incubation because of their flexibility to environmental changes.

Our previous study showed that Sulfurimonas denitrificans was the SOB dominated during the incubation of the launched marine sediment under nitrate-reducing conditions 
(Aoyagi et al., 2015). On the other hand, exposure of the sediment to the oxic conditions resulted in the proliferation of more diverse dominant SOB than those under nitrate-reducing conditions (Table 3). Sulfate accumulation rate in the previous study $(1800 \mathrm{mg} / \mathrm{kg}$ wet weight (ww)/day) was almost 6 times faster than the present one $(300 \mathrm{mg} / \mathrm{kg}$ ww/day), presumably due to the difference of the experimental conditions: in the previous study, sediment was suspended as slurry and anaerobically pre-incubated for 1-month before addition of nitrate. Out of the predominant OTUs found in the uppermost layer of the incubated sediment in this study, 8 OTUs (OTU 43060, 25387, 21731, 36501, 30483, 45161, 16111, and 45198) were phylogenetically related to SOB. In particular, Sulfurimonas autotrophica, Sulfurovum lithotrophicum, Sulfurovum aggregans and Thiomicrospira crunogena have been isolated from deepsea sediments and/or hydrothermal vents (Jannasch et al., 1985; Inagaki et al., 2003, 2004; Mino et al., 2014). Other two dominant OTUs 32337 and 6816 in the uppermost layer were phylogenetically related to FeOB. The related species $M$. ferrooxydans has been isolated from hydrothermal vents and they have been known as important players in ecological iron cycling (Emerson et al., 2007; Hoshino et al., 2016). Thus, it is likely that the launched marine sediment examined harbor SOB and FeOB, both of which have been found in these aquatic ecosystems.

Dramatic environmental changes of the launched marine sediment, particularly the exposure to atmosphere, may cause strong effects geochemically and biologically. For example, the on-site sediment surface colored reddish brown (Figure S2), resulting from the formation of iron precipitates. The on-site detection of $\mathrm{SOB}$ and FeOB suggested that metabolic activities of these bacteria were related to the direct and/or indirect formation of iron precipitate because of the close relationship between the iron and sulfur cycling (Jørgensen and Fenchel, 1974; Jørgensen, 1977; Hsieh and Yang, 1989; Schippers and Jørgensen, 2002). Indeed, the laboratory incubation of the sediment showed the rapid increase and decrease of FeOB-related OTUs (Figure 3 and Table 3).

Heavy metals are generally preserved as metal sulfides in coastal marine sediments due to hydrogen sulfide produced by SRB (Jørgensen, 1977; Zhang et al., 2014). Relatively high metal concentrations of the launched sediment were comparable with those found in marine sediment in the Ishinomaki bay that is near the sampling site (Table 2, Imai et al., 2004). The uppermost layer exhibited apparently lower concentrations of the metals than the deep layer, which suggests that the heavy-metal mobilization was facilitated by the natural weathering of the sediment in the terrestrial environment. Both the on-site and laboratory studies demonstrated the dramatic proliferation of SOB under oxic conditions in the sediment (Figures 1, 3). The sulfur oxidation could be directly linked to the release of heavy metals from metal sulfides, as reported previously (Gadd, 2000, 2004; Sand et al., 2001; Stephens et al., 2001). Moreover, the production of sulfate from sulfur oxidation resulted in the acidification of the sediment (Figure 4). The leaching of metals at low $\mathrm{pH}$ has been reported previously (Evans, 1989; Masscheleyn et al., 1991; Calmano et al., 1993; Bowell, 1994). Thus, SOB might cause the mobilization of heavy metals via the direct and indirect procedures in the

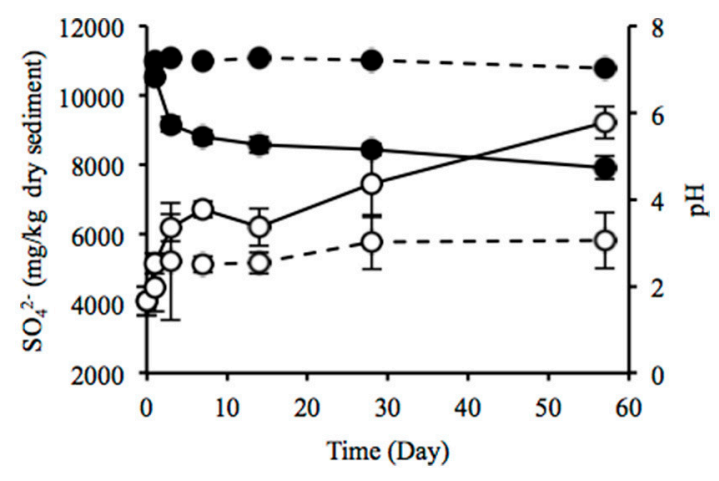

FIGURE 4 | Time-course changes in sulfate ion concentration (open circles) and $\mathrm{pH}$ (filled circles) of the sediments incubated in laboratory. Solid and dotted lines indicate data in the uppermost (0-2 mm depth) and deep (12-16 mm depth) layers of the sediments. Error bars indicate standard deviations of four replications. Only sulfate ion concentrations in the uppermost layers at days 1 and 57 were conducted in triplicate.

sediment. The time-dependent changes in sulfur compounds and heavy metals in the sediment will be necessary to clarify the involvement of SOB in these processes.

Although the launched marine sediment was rich in organic matters, chemoorganotrophic bacteria became dominant after the proliferation of chemolithotrophic $\mathrm{SOB}$ and $\mathrm{FeOB}$ (Figure 3 and Table 3). Most of the organic substances in marine sediment have been considered as being relatively persistent (Kristensen et al., 1995; Kristensen, 2000), suggesting the organic substances available for chemoorganotrophic bacteria was limited in this study. In fact, no obvious decreases in IL, TC and TN were observed during the laboratory incubation (Figures S5A-C). The increase in TC in the uppermost layer over the time course of the incubation suggests that $\mathrm{SOB}$ and $\mathrm{FeOB}$ fixed $\mathrm{CO}_{2}$ as a carbon source and biosynthesized organic substances (Figure S5B). SOB might facilitate the growth of chemoorganotrophic bacteria by supplementing the easily degradable organic substances for them. Because the accumulation of organic matters on the seafloor can adversely affect the ecosystem, it has long been a challenge to stimulate the degradation of organically enriched marine sediment by biological and chemical procedures (Vezzulli et al., 2004; Kunihiro et al., 2008; Wada et al., 2008; Yamamoto et al., 2008; Laverock et al., 2010).

We herein clarified the succession of microbial communities in the launched marine sediment by combining the longterm on-site survey and short-term laboratory incubation. Although the laboratory incubation was unable to recreate the on-site environment in its entirety, it provided the important information about the change of microbial communities due to the exposure to atmosphere. A variety of SOB, especially the class Epsilonproteobacteria, rapidly proliferated and induced the subsequent growth of FeOB and chemoorganotrophic bacteria. Furthermore, the metabolically activated SOB possibly contributed to the mobilization of heavy metals that bound to the sediment. Consequently, the epsilonproteobacterial SOB initiated the dynamic shift 
from the anaerobic to aerobic microbial communities, which play a pivotal role in element cycling in the marine sediment.

\section{AUTHOR CONTRIBUTIONS}

HI: Main worker in this paper. TH and TA: Contribution for DNA analysis and discussion. MT: Contribution for sampling and discussion. YK: Supervisor of the first author, and contribution for discussion.

\section{REFERENCES}

Aoyagi, T., Kimura, M., Yamada, N., Navarro, R. R., Itoh, H., Ogata, A., et al. (2015). Dynamic transition of chemolithotrophic sulfur-oxidizing bacteria in response to amendment with nitrate in deposited marine sediments. Front. Microbiol. 6:426. doi: 10.3389/fmicb.2015.00426

Asano, R., Nakai, Y., Kawada, W., Shimura, Y., Inamoto, T., and Fukushima, J. (2013). Seawater inundation from the 2011 Tohoku tsunami continues to strongly affect soil bacterial communities 1 year later. Microb. Ecol. 66, 639-646. doi: 10.1007/s00248-013-0261-9

Bowell, R. J. (1994). Sorption of arsenic by iron oxides and oxyhydroxides in soils. Appl. Geochem. 9, 279-286. doi: 10.1016/0883-2927(94)90038-8

Bowman, J. P. (2005). "Order VII. Methylococcales ord. nov." in Bergey's Manual of Systematic Bacteriology, Vol. 2, The Proteobacteria Part B, 2nd Edn., eds D. J. Brenner, N. R. Krieg, J. T. Staley, and G. M. Garrity (New York, NY: Springer), 248.

Calmano, W., Hong, J., and Förstner, U. (1993). Binding and mobilization of heavy metals in contaminated sediments affected by $\mathrm{pH}$ and redox potential. Wat. Sci. Technol. 28, 223-235.

Caporaso, J. G., Kuczynski, J., Stombaugh, J., Bittinger, K., Bushman, F. D., Costello, E. K., et al. (2010). QIIME allows analysis of highthroughput community sequencing data. Nat. Methods 7, 335-336. doi: $10.1038 /$ nmeth.f.303

Caporaso, J. G., Lauber, C. L., Walters, W. A., Berg-Lyons, D., Huntley, J., Fierer, N., et al. (2012). Ultra-high-throughput microbial community analysis on the Illumina HiSeq and MiSeq platforms. ISME J. 6, 1621-1624. doi: 10.1038/ismej.2012.8

Caporaso, J. G., Lauber, C. L., Walters, W. A., Berg-Lyons, D., Lozupone, C. A., Turnbaugh, P. J., et al. (2011). Global patterns of $16 \mathrm{~S}$ rRNA diversity at a depth of millions of sequences per sample. Proc. Natl. Acad. Sci. U.S.A. 108 , 4516-4522. doi: 10.1073/pnas.1000080107

Cloern, J. E. (2001). Our evolving conceptual model of the coastal eutrophication problem. Mar. Ecol. Prog. Ser. 210, 223-253. doi: 10.3354/meps 210223

Dyksma, S., Bischof, K., Fuchs, B. M., Hoffmann, K., Meier, D., Meyerdierks, A., et al. (2016). Ubiquitous Gammaproteobacteria dominate dark carbon fixation in coastal sediments. ISME J. 12, 1-15. doi: 10.1038/ismej.2015.257

Emerson, D., Rentz, J. A., Liburn, T. G., Davis, R. E., Aldrich, H., Chan, C., et al. (2007). A novel lineage of proteobacteria involved in formation of marine Fe-oxidizing microbial mat communities. PLoS ONE 2:e667. doi: 10.1371 /journal.pone. 0000667

Evans, L. J. (1989). Chemistry of metal retention by soils. Environ. Sci. Technol. 23, 1046-1056. doi: 10.1021/es00067a001

Gadd, G. M. (2000). Bioremedial potential of microbial mechanisms of metal mobilization and immobilization. Curr. Opin. Biotechnol. 11, 271-279. doi: 10.1016/S0958-1669(00)00095-1

Gadd, G. M. (2004). Microbial influence on metal mobility and application for bioremediation. Geoderma 122, 109-119. doi: 10.1016/j.geoderma.2004. 01.002

Hallbeck, L. E. L., and Pedersen, K. (2005). "Genus I. Gallionella," in Bergey's Manual of Systematic Bacteriology, Vol. 2, The Proteobacteria Part C, 2nd Edn., eds D. J. Brenner, N. R. Krieg, J. T. Staley, and G. M. Garrity (New York, NY: Springer), $880-886$.

\section{ACKNOWLEDGMENTS}

We thank Izumi Watanabe in Tokyo University of Agriculture and Technology for support of metal analysis.

\section{SUPPLEMENTARY MATERIAL}

The Supplementary Material for this article can be found online at: http://journal.frontiersin.org/article/10.3389/fmicb. 2017.00152/full\#supplementary-material

Holmer, M., and Kristensen, E. (1992). Impact of marine fish cage farming on metabolism and sulfate reduction of underlying sediments. Mar. Ecol. Prog. Ser. 80, 191-201. doi: 10.3354/meps080191

Hori, T., Kimura, M., Aoyagi, T., Navarro, R. R., Ogata, A., Sakoda, A., et al. (2014). Biodegradation potential of organically enriched sediments under sulfate- and iron-reducing conditions as revealed by the $16 \mathrm{~S}$ rRNA deep sequencing. J. Water Environ. Technol. 12, 357-366. doi: 10.2965/jwet. 2014.357

Hoshino, T., Kuratomi, T., Morono, Y., Hori, T., Oiwane, H., Kiyokawa, S., et al. (2016). Ecophysiology of Zetaproteobacteria associated with shallow hydrothermal iron- oxyhydroxide deposits in Nagahama Bay of Satsuma IwoJima, Japan. Front. Microbiol. 6:1554. doi: 10.3389/fmicb.2015.01554

Hsieh, Y. P., and Yang, C. H. (1989). Diffusion methods for the determination of reduced inorganic sulfur species in sediments. Limnol. Oceanogr. 34, 1126-1130. doi: 10.4319/lo.1989.34.6.1126

Iimura, K. (1981). "Background contents of heavy metals in Japanese soils," in Heavy Metal Pollution in Soils of Japan, eds K. Kitagishi and I. Yamane (Tokyo: Japan Scientific Societies Press), 19-26.

Imai, N., Terashima, S., Ohata, M., Mikoshiba, Y., Okai, T., Tachibana, Y., et al. (2004). Geochemical Map of Sea and Land of Japan. Tsukuba: Geological Survey of Japan AIST.

Inagaki, F., Takai, K., Kobayashi, H., Nealson, K. H., and Horikoshi, K. (2003). Sulfurimonas autotrophica gen. nov., sp. nov., a novel sulfur-oxidizing $\epsilon$ proteobacterium isolated from hydrothermal sediments in the Mid-Okinawa Trough. Int. J. Syst. Evol. Microbiol. 53, 1801-1805. doi: 10.1099/ijs.0.02682-0

Inagaki, F., Takai, K., Nealson, K. H., and Horikoshi, K. (2004). Sulfurovum lithotrophicum gen. nov., sp. nov., a novel sulfur-oxidizing chemolithoautotroph within the $\epsilon$-Proteobacteria isolated from Okinawa Trough hydrothermal sediments. Int. J. Syst. Evol. Microbiol. 54, 1477-1482. doi: 10.1099/ijs.0.03042-0

Itoh, H., Aita, M., Nagayama, A., Meng, X. Y., Kamagata, Y., Navarro, R., et al. (2014). Evidence of environmental and vertical transmission of Burkholderia symbionts in the oriental chinch bug, Cavelerius saccharivorus (Heteroptera: Blissidae). Appl. Environ. Microbiol. 80, 5974-5983. doi: 10.1128/AEM.01087-14

Jannasch, H. W., Wirsen, C. O., Nelson, D. C., and Robertson, L. A. (1985) Thiomicrospira crunogena sp. nov., a colorless, sulfur-oxidizing bacterium from a deep-sea hydrothermal vent. Int. J. Syst. Bacteriol. 35, 422-424. doi: 10.1099/00207713-35-4-422

Jørgensen, B. B. (1977). The sulfur cycle of a coastal marine sediment (Limfjorden Denmark). Limnol. Oceanogr. 22, 814-832. doi: 10.4319/lo.1977.22.5.0814

Jørgensen, B. B., and Fenchel, T. (1974). The sulfur cycle of a marine sediment model system. Mar. Biol. 24, 189-201. doi: 10.1007/BF00391893

Kämpfer, P. (2012). “Order XIV. Streptomycetales ord. nov.” in Bergey's Manual of Systematic Bacteriology, Vol. 5, The Actinobacteria Part B, 2nd Edn., eds M. Goodfellow, P. Kämpfer, H. Busse, M. E. Trujillo, K. Suzuki, W. Kudwig, et al. (New York, NY: Springer), 1446.

Kawabe, Y., Hara, J., Yasutaka, T., Sakamoto, Y., Zhang, M., and Komai, T. (2012). Heavy metals in tsunami sediment by the Great East Japan Earthquake and their risks to human. J. Jpn. Soc. Civ. Eng. Ser. G. Environ. Res. 68, 195-202. doi: 10.2208/jscejer.68.195

Kodama, Y., and Watanabe, K. (2004). Sulfuricurvum kujiense gen. nov., sp. nov., a facultatively anaerobic, chemolithoautotrophic, sulfur-oxidizing bacterium 
isolated from an underground crude-oil storage cavity. Int. J. Syst. Evol. Microbiol. 54, 2297-2300. doi: 10.1099/ijs.0.63243-0

Kristensen, E. (2000). Organic matter diagenesis at the oxic/anoxic interface in coastal marine sediments, with emphasis on the role of burrowing animals. Hydrobiologia 426, 1-24. doi: 10.1023/A:1003980226194

Kristensen, E., Ahmed, S. I., and Devol, A. H. (1995). Aerobic and anaerobic decomposition of organic matter in marine sediment: which is fastest? Limnol. Oceanogr. 40, 1430-1437. doi: 10.4319/lo.1995.40.8.1430

Kunihiro, T., Miyazaki, T., Uramoto, Y., Kinoshita, K., Inoue, A., Tamaki, S., et al. (2008). The succession of microbial community in the organic rich fishfarm sediment during bioremediation by introducing artificially mass-cultured colonies of a small polychaete, Capitella sp. I. Mar. Pollut. Bull. 57, 68-77. doi: 10.1016/j.marpolbul.2007.10.009

Laverock, B., Smith, C. J., Tait, K., Osborn, A. M., Widdicombe, S., and Gilbert, J. A. (2010). Bioturbating shrimp alter the structure and diversity of bacterial communities in coastal marine sediments. ISME J. 4, 1531-1544. doi: 10.1038 /ismej.2010.86

Lenk, S., Arnds, J., Zerjatke, K., Musat, N., Amann, R., and Mussmann, M. (2011). Novel groups of Gammaproteobacteria catalyse sulfur oxidation and carbon fixation in a coastal, intertidal sediment. Environ. Microbiol. 13, 758-774. doi: 10.1111/j.1462-2920.2010.02380.x

Lenk, S., Moraru, C., Hahnke, S., Arnds, J., Richter, M., Kube, M., et al. (2012). Roseobacter clade bacteria are abundant in coastal sediments and encode a novel combination of sulfur oxidation genes. ISME J. 6, 2178-2187. doi: 10.1038/ismej.2012.66

Mahmoudi, N., Robeson, M. S. II, Castro, H. F., Fortney, J. L., Techtmann, S. M., Joyner, D. C., et al. (2015). Microbial community composition and diversity in Caspian Sea sediments. FEMS Microbiol. Ecol. 91, 1-11. doi: 10.1093/femsec/fiu013

Masscheleyn, P. H., Delaune, R. D., and Patrick, W. H. Jr. (1991). Effect of redox potential and $\mathrm{pH}$ on arsenic speciation and solubility in a contaminated soil. Environ. Sci. Technol. 25, 1414-1419. doi: 10.1021/es00020a008

Middelburg, J. J., Vlug, T., and Van der Nat, F. J. W. A. (1993). Organic matter mineralization in marine systems. Global. Planet. Change. 8, 47-58. doi: 10.1016/0921-8181(93)90062-S

Mimura, N., Yasuhara, K., Kawagoe, S., Yokoki, H., and Kazama, S. (2011). Damage from the Great East Japan Earthquake and Tsunami - a quick report. Mitig. Adapt. Strateg. Glob. Change 16, 803-818. doi: 10.1007/s11027-011-9297-7

Ministry of the Environment (2011). Properties of Tsunami Deposits [in Japanese] Available online at: http://www.env.go.jp/jishin/attach/sisin110713_r1.pdf

Mino, S., Kudo, H., Arai, T., Sawabe, T., Takai, K., and Nakagawa, S. (2014). Sulfurovum aggregans sp. nov., a hydrogen-oxidizing, thiosulfatereducing chemolithoautotroph within the Epsilonproteobacteria isolated from a deep-sea hydrothermal vent chimney, and an emended description of the genus Sulfurovum. Int. J. Syst. Evol. Microbiol. 64, 3195-3201. doi: 10.1099/ijs.0.065094-0

Morse, J. W., and Luther, G. W. (1999). Chemical influences on trace metal-sulfide interactions in anoxic sediments. Geochim. Cosmochim. Acta 63, 3373-3378. doi: 10.1016/S0016-7037(99)00258-6

Nakamura, K., Kuwatani, T., Kawabe, Y., and Komai, T. (2016). Extraction of heavy metals characteristics of the 2011 Tohoku tsunami deposits using multiple classification analysis. Chemosphere 144, 1241-1248. doi: 10.1016/j.chemosphere.2015.09.078

Navarro, R. R., Aoyagi, T., Kimura, M., Itoh, H., Sato, Y., Kikuchi, Y., et al. (2015). High-resolution dynamics of microbial communities during dissimilatory selenate reduction in anoxic soil. Environ. Sci. Technol. 49, 7684-7691. doi: $10.1021 / \mathrm{es} 505210 \mathrm{p}$

Noll, M., Matthies, D., Frenzel, P., Derakshani, M., and Liesack, W. (2005). Succession of bacterial community structure and diversity in a paddy soil oxygen gradient. Environ. Microbiol. 7, 382-395. doi: 10.1111/j.1462-2920.2005.00700.x

Saddler, G. S., and Bradbury, J. F. (2005). “Order III. Xanthomonadales ord. nov.” in Bergey's Manual of Systematic Bacteriology, Vol. 2, The Proteobacteria Part B, 2nd Edn., ed. D. J. Brenner, N. R. Krieg, J. T. Staley, and G. M. Garrity (New York, NY: Springer), 63.
Sand, W., Gehrke, T., Jozsa, P. G., and Schippers, A. (2001). (Bio) chemistry of bacterial leaching-direct vs. indirect bioleaching. Hydrometallurgy 59, 159-175. doi: 10.1016/S0304-386X(00)00180-8

Schippers, A., and Jørgensen, B. B. (2002). Biogeochemistry of pyrite and iron sulfide oxidation in marine sediments. Geochim. Cosmochim. Acta 66, 85-92. doi: 10.1016/S0016-7037(01)00745-1

Schloss, P. D., Westcott, S. L., Ryabin, T., Hall, J. R., Hartmann, M., Hollister, E. B., et al. (2009). Introducing mother: open-source, platformindependent, community-supported software for describing and comparing microbial communities. Appl. Environ. Microbiol. 75, 7537-7541. doi: 10.1128/AEM.01541-09

Seitaj, D., Schauer, R., Sulu-Gambari, F., Hidalgo-Martinez, S., Malkin, S. Y., Burdorf, L. D. W., et al. (2015). Cable bacteria generate a firewall against euxinia in seasonally hypoxic basins. Proc. Natl. Acad. Sci. U.S.A. 112, 13278-13283. doi: 10.1073/pnas.1510152112

Sera, K., Baba, F., Goto, S., Takahashi, C., and Saitoh, Y. (2011). Analysis of contaminated sludge deposited on the land attacked by great tsunami following Tohoku great earthquake disaster. NMCC Annu. Rep. 18, 84-92.

Sera, K., Goto, S., Takahashi, C., Saitoh, Y., and Yamauchi, K. (2014). Effects of heavy elements in the sludge conveyed by the 2011 tsunami on human health and the recovery of the marine ecosystem. Nucl. Instrum. Meth. B 318, 76-82. doi: 10.1016/j.nimb.2013.06.062

Stephens, S. R., Alloway, B. J., Parker, A., Carter, J. E., and Hodson, M. E. (2001). Changes in the leachability of metals form dredged canal sediments during drying and oxidation. Environ. Pollut. 114, 407-413. doi: 10.1016/S0269-7491(00)00231-1

Tanaka, G., Naruse, H., Yamashita, S., and Arai, K. (2012). Ostracodes reveal the sea-bed origin of tsunami deposits. Geophys. Res. Lett. 39:L05406. doi: 10.1029/2012GL051320

Tsuchiya, N., Inoue, C., Yamada, R., Yamasaki, S., Hirano, N., Okamoto, A., et al. (2012). Risk assessments of arsenic in tsunami sediments from Iwate, Miyagi and Fukushima prefectures, Northeast Japan, by the 2011 off the Pacific coast of Tohoku Earthquake. J. Geol. Soc. Jpn. 118, 419-430. doi: 10.5575/geosoc.2012.0043

Vezzulli, L., Pruzzo, C., and Fabiano, M. (2004). Response of the bacterial community to in situ bioremediation of organic-rich sediments. Mar. Pollut. Bull. 49, 740-751. doi: 10.1016/j.marpolbul.2004.05.010

Wada, M., Zhang, D., Do, H. K., Nishimura, M., Tsutsumi, H., and Kogure, K. (2008). Co-inoculation of Capitella sp. I with its synergistic bacteria enhances degradation of organic matter in organically enriched sediment below fish farms. Mar. Pollut. Bull. 57, 86-93. doi: 10.1016/j.marpolbul.2007. 10.004

Yamamoto, M., and Takai, K. (2011). Sulfur metabolisms in epsilon-and gammaProteobacteria in deep-sea hydrothermal fields. Front. Microbiol. 2:192. doi: 10.3389/fmicb.2011.00192

Yamamoto, T., Goto, I., Kawaguchi, O., Minagawa, K., Ariyoshi, E., and Matsuda, O. (2008). Phytoremediation of shallow organically enriched marine sediments using benthic microalgae. Mar. Pollut. Bull. 57, 108-115. doi: 10.1016/j.marpolbul.2007.10.006

Zhang, C., Yu, Z. G., Zeng, G. M., Jiang, M., Yang, Z. Z., Cui, F., et al. (2014). Effects of sediment geochemical properties on heavy metal bioavailability. Environ. Int. 73, 270-281. doi: 10.1016/j.envint.2014.08.010

Conflict of Interest Statement: The authors declare that the research was conducted in the absence of any commercial or financial relationships that could be construed as a potential conflict of interest.

Copyright (๑) 2017 Ihara, Hori, Aoyagi, Takasaki and Katayama. This is an openaccess article distributed under the terms of the Creative Commons Attribution License (CC BY). The use, distribution or reproduction in other forums is permitted, provided the original author(s) or licensor are credited and that the original publication in this journal is cited, in accordance with accepted academic practice. No use, distribution or reproduction is permitted which does not comply with these terms. 